\title{
A Streptomycin-Resistant Line of Nicotiana sylvestris Unable to Flower
}

\author{
P. Maliga, Zsuzsa R.-Kiss, P.J. Dix, and Gabriella Lázár \\ Institute of Plant Physiology, Biological Research Center, H-6701 Szeged, P.O. Box 521, Hungary
}

Summary. A streptomycin-resistant cell line, SR155, was selected in a callus culture initiated from diploid Nicotiana sylvestris.

Regenerates of the SR155 line have a grossly altered morphology, an altered peroxidase isoenzyme pattern, and do not flower. The SR155 plants are diploid, but in the karyotype a chromosome translocation was detected.

\section{Introduction}

The understanding of the structure and function of chloroplasts and mitochondria of higher plants may be facilitated by mutations in the organelle DNAs. Streptomycin resistans are among the potentially useful mutant types. Such cell lines have been isolated in tissue cultures of Petunia hybrida (Binding et al., 1970; Binding, 1972), Nicotiana tabacum (Maliga et al., 1973; 1975; Umiel and Goldner, 1976) and Nicotiana sylvestris (Dix et al., 1977). Plant regeneration was possible only in two $N$. tabacum lines, SRI (Maliga et al., 1973; 1975) and St-R701 (Umiel, 1978) and maternal inheritance of the resistance trait was demonstrated. In the SR1 mutant, no other changes than alteration of the chloroplast ribosomes (Bourque et al., 1977; Yurina et al., 1978) could be shown.

In this paper we describe another streptomycinresistant line selected in a different species, Nicotiana sylvestris. Regenerated plants in this case, however, have altered in many respects including the ability to flower.

Present address: Department of Genetics, University of Newcastle, Newcastle-upon-Tyne NE1 7RU, U.K.

For offprints contact: Dr. P. Maliga, Institute of Plant Physiology, H-6701 Szeged, P.O.B.521, Hungary

\section{Materials and Methods}

Tissue Culture

Selection was carried out in Petri dishes by inoculating callus pieces $(30 \mathrm{mg}$ ) onto a Linsmaier and Skoog RM medium modified to contain $0.5 \mathrm{mg}$ benzylaminopurine and $2 \mathrm{mg}$ indole-3-acetic acid per liter (RMO medium; Maliga et al., 1973). Shoots were rooted on this medium minus growth regulators (RM medium).

Callus cultures were incubated at $28^{\circ} \mathrm{C}$, at light intensities of 2,000 lux.

\section{Selection of the Line}

Calli grown from diploid $2 n=2 X=24$ seedlings were inoculated onto RMO medium containing $500 \mu \mathrm{g} \mathrm{ml}^{-1}$ streptymicin sulphate. Streptomycin at this concentration streongly, but not completely, inhibits growth and greening. The SR 155 line was selected by its faster growth and green pigmentation on this selective medium as described previously (Maliga et al., 1973]. Plants, regenerated from the resistant callus retained resistance as indicated by the growth on selective medium of green callus from leaf sections of the regenerates.

\section{Cytology}

Root tips were pretreated for $4 \mathrm{~h}$ in $0.05 \%$ colchicine at room temperature and fixed overnight in absolute ethanol: glacial acetic acid $(3: 1)$. The root tips were then washed in distilled water, hydrolysed for $10 \mathrm{~min}$ in $1 \mathrm{M} \mathrm{HCl}$ at $60^{\circ} \mathrm{C}$ and squashed in acetocarmine ( $5 \mathrm{~g}$ carmine dissolved in $100 \mathrm{ml} 45 \%$ acetic acid).

\section{Isoenzymes}

Isoenzymes were separated by polyacrylamide gel electrophoresis: the esterases and alcohol dehydrogenases as described by Maliga et al. (1977), the peroxidases according to Maliga et al. (1976).

\section{Results}

\section{Morphology and Flowering of the Regenerates}

The morphology of SR155 plants is uniform and is distinctly different from the original diploid $N . s y l$ 

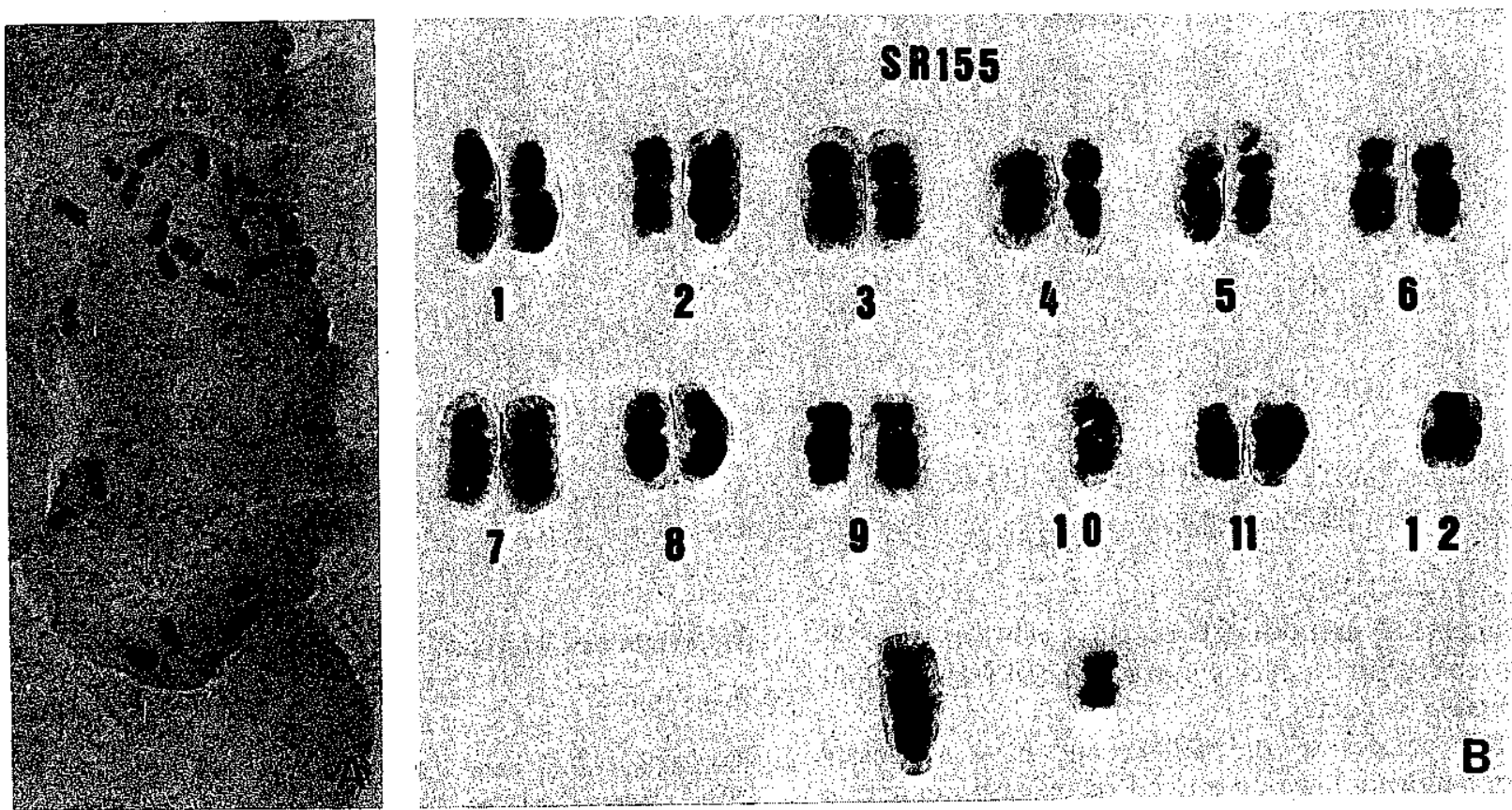

Fig. 1 A and B. A metaphase plate in a root tip cell (A) and the karyotype (B) of an SR155 plant. Magnification: $1500 X$ (A)
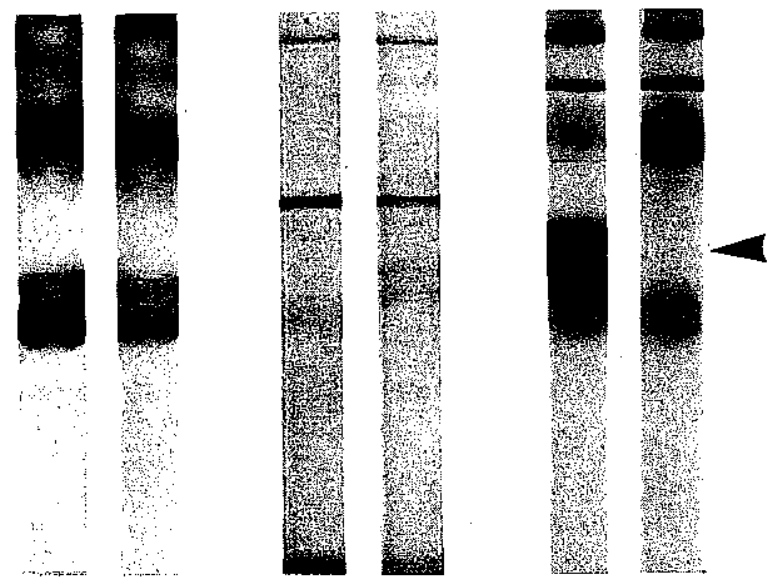

\section{A}

B

C

Fig, 2 A-C. Esterase (A), alcohol dehydrogenase (B) and peroxidase (C) isoenzymes from the leaves of normal $N$. sylvestris (left) and SR155 plants. Note the absence of a peroxidase band from SR155 (arrow). Leaves were taken from plants grown in sterile culture

vestris plants. The leaves of the SR 155 plants are smaller, narrower and have an irregular system of veins. N. sylvestris requires long days for flowering and remains in the rosette stage under short days. The SR 155 plants stay in the rosette stage whatever the light regime. Since 1975 more than five hundred SR155 individuals have been grown in the greenhouse for at least eight months each, but small buds developed on only two of them. These buds which appeared under long-day conditions, turned brown and fell off before reaching $3 \mathrm{~mm}$ in diameter. The appearance of the buds in these two plants was not followed by the usual stem elongation.

\section{The SR155 Karyotype}

Aberrant morphology in Nicotiana may be in consequence of aneuploid chromosome numbers, observed frequently with plants regenerated after long cultivation periods (Melchers, 1965; Sacristán and Melchers, 1969). In metaphase plates of the SR 155 cells 24 chromosomes were found, the same number contained by the diploid plants from which the cultures were initiated for selection. Aneuploid deviation, therefore, was not responsible for the altered morphology. When trying to identify the chromosomes by size and arm ratios, however, a long subtelocentric and a small metacentric chromosome were found (Fig. 1) which are missing from the karyotype of the unselected $N$. sylvestris plants. These chromosomes must have resulted from a translocation.

\section{Isoenzymes}

The isoenzymes which are routinally studied in this laboratory were studied from the leaves of the SR 155 
plants in the hope of finding deviation from the standard N. sylvestris patterns, which could be exploited in intraspecific fusion experiments.

The esterase and the alcohol dehydrogenase patterns were unaltered in the SR155 plants (Fig. 2a, b). After the electrophoresis of the SR155 leaf extracts, however, no peroxidase activity was found at the position which corresponds to the major peroxidase band in unselected $N$. sylvestris. The major SR155 peroxidase migrated slower in the gel, and was found at the position of a minor band in N. sylvestris (Fig. 2c).

\section{Discussion}

The SR155 line was selected in a diploid $N$. sylvestris culture through its green pigmentation and faster growth on streptomycin medium. With respect to the response to streptomycin in culture, maintenance of the resistance after plant regeneration, and streptomycin uptake and inactivation (data not shown) SR 155 accords with a previous isolate, SR1, selected by the same procedure from N. Tabacum (Maliga et al., 1973, 1975).

Alterations in the electrophoretic mobility of leaf peroxidases, karyotypic changes, altered morphology and lack of flowering ability, however, are absent from the SR1 mutant (Maliga et al., 1973, 1975; unpublished).

Translocations and other changes in the karyotype of cultured cells are well documented, and are more frequent than in plants (Shimada and Tabata, 1967; Sacristán, 1971; for review see Sunderland, 1973). There may also be genetic changes (mutations) which cannot be detected by cytological methods (Melchers, 1965). The translocation, and the appearance of unselected new traits in the case of the SR155 line are not surprising therefore, and may be considered as consequences of the application of tissue culture. It cannot be excluded, however, that at least some of these changes are the result of the same event which led to streptomycin resistance in SR155, and this will be investigated.

Acknowledgement. This research was supported in part by the OMFB grant No. $79978 / 28 / 22-2764$.

\section{References}

Binding, H.: Selektion in Kalluskulturen mit haploiden Zellen. Z. Pflanzenzüchtg. 67, 33-38 (1972)

Binding, H., Binding, K., Straub, J.: Selektion in Gewebekulturen mit Haploiden. Naturwissenschaften 57, 138-139 (1970)

Bourque, D.P., Horn, N.A., Capel, M.S. : Altered chloroplast ribosome of a streptomycin resistant mutant of Nicotiana tabacum. Plant Physiol. 59, (Suppl.) 110 (1977)

Dix, P.J., Joó, F., Maliga, P.: A cell line of Nicotiana sylvestris with resistance to kanamycin and streptomycin. Mol. Gen. Genet. 157, 285-290 (1977)

Maliga, P., Lázár, G., Joó, F., H.-Nagy, A., Menczel, L.: Restoration of morphogenic potential in Nicotiana by somatic hybridisation. Mol. Gen. Genet. 157, 291-296 (1977)

Maliga, P., Lázár, G., Sváb, Z., Nagy, F.: Transient cycloheximide resistance in a tobacco cell line. Mol. Gen. Genet. 149, 267-271 (1976)

Maliga, P., Sz.-Breznovits, Á., Márton, L.: Streptomycin resistant plants from callus culture of haploid tobacco. Nature (New Biol.) 244, 29-30 (1973)

Maliga, P., Sz.-Breznovits, Á., Márton, L.: Non-Mendelian streptomycin-resistant tobacco mutant with altered chloroplasts and mitochondria. Nature 255, 401-402 (1975)

Melchers, G.: Einige genetische Gesichtspunkte zu sogenannten Gewebekulturen. Ber. Dtsch. bot. Ges. 78, 21-29 (1965)

Sacristán, M.D.: Karyotypic changes in callus cultures from haploid and diploid plants of Crepis capillaris (L) Wallr. Chromosoma 33, 273-283 (1971)

Sacristán, M.D., Melchers, G.: The caryological analysis of plants regenerated from tumorous and other callus cultures of tobacco. Mol. Gen. Genet. 105, 317-333 (1969)

Shimada, T., Tabata, M.: Chromosome numbers in cultured pith tissues of tobacco. Jpn. J. Genet. 42, 195-201 (1967)

Sunderland, N.: Nuclear cytology. In: Plant tissue and cell culture (Street, H.E., ed.), pp. 161-190. Oxford: Blackwell 1973

Umiel, N.: The isolation of mutants in plant tissue cultures, and their use in gentic studies and plant breeding. In: Production of natural compounds by cell culture methods (Alfermann, A.W., Reinhard, E. eds.), pp. 346-352. München: Gesellschaft für Strahlen- und Umweltforschung MBH 1978

Umiel, N., Goldner, R. : Effects of streptomycin on diploid tobacco callus cultures and the isolation of resistant mutants. Protoplasma 89, 83-89 (1976)

Yurina, N.P., Oditsova, M.S., Maliga, P.: An altered chloroplast ribosomal protein in a streptomycin resistant tobacco mutant. Theor. Appl. Genet. 52, 125-128 (1978)

Communicated by G. Melchers

Received November 13, 1978 / January 11, 1979 